\title{
EL PATRIMONIO DE LA INDUSTRIA: UN REFERENTE TURÍSTICO POR EXPLORAR EN LA REGIÓN DE MURCIA
}

\author{
María Dolores Palazón Botella
}

Universidad de Murcia

\section{RESUMEN}

Los procesos industriales están sujetos a la evolución de los tiempos quienes, tras servirse de ellos atendiendo a su función original, han comenzado a adaptarse a las nuevas demandas transformándose en referentes patrimoniales y turísticos que permiten diversificar y completar su proyección inicial. Es una cuestión que se está implementando tal y como testimonia la Región de Murcia (España), donde su sustrato industrial, pretérito y actual, está siendo protagonista de propuestas que pretenden incentivar el turismo industrial. Analizar las opciones que se han implantado para potenciar las actividades turísticas sobre el mismo y fijar las pautas para su progresión nos permitirá obtener tanto un estudio de estas propuestas, como marcar una línea de trabajo futura que puede revertir de manera efectiva en la diversificación de la oferta turística regional, y por ende, reforzar la salvaguarda y difusión de su industria.

Palabras clave: Turismo industrial; patrimonio industrial; empresa; difusión; oferta turística.

The heritage of the industry: a tourist referent to explore in the Region of Murcia

\section{ABSTRACT}

The industrial processes are subject to the evolution of the times, which, after making use of them in response to their original function, have started to adapt to the new demands, transforming into patrimonial and touristic references that allow to diversification and complete their initial mission. This is an issue that is being introduced, as testified by the

Recibido: 25 de abril de 2016

Devuelto para su revisión: 10 de octubre de 2016

Aceptado: 7 de febrero de 2017

Departamento de Historia del Arte. Universidad de Murcia. Campus de La Merced. 30001 MURCIA (España).E-mail: mdolorespb@um.es 
Region of Murcia (Spain), where its past and current industrial substrate is being at the fore of proposals that expect to stimulate industrial tourism. To analyse the options that have been introduced in order to boost tourist activities on the same subject, and to provide the guidelines for its progression will allow us to obtain not only a study of the proposals, but also to draw a future working line that can reverse meaningfully in the diversification of the tourist regional offers, and for that matter, strengthen the safeguard and diffusion of its industry.

Keywords: Industrial tourism; industrial heritage; company; diffusion; tourist offer.

\section{LA REGIÓN DE MURCIA FRENTE A SU INDUSTRIA}

La Región de Murcia es un testimonio de la historia industrial de nuestro país, de su problemática y progresión, sumando capítulos de avance y retroceso (Martínez, 2002). Pese a ello hasta fechas recientes ha primado el calificativo de intrascendente a la hora de valorar su participación en el panorama industrializador nacional, al no tener en cuenta que este proceso no atendió a unos criterios homogéneos, sino que dentro de unos patrones comunes se adaptó a la realidad de los lugares en los que irradió (Nadal, Catalán, 1994). De hecho su desarrollo industrial se inició en el XVIII, momento en el que el Arsenal de Cartagena comenzó a construirse (1731) y a conformarse las fábricas de pólvora (Javalí Viejo, 1747) y salitre (Murcia y Lorca). Años en los que también emergería la actividad textil sedera en la ciudad de Murcia de manos de las fábricas de la Piamontesa (1770) y la Tolonesa. Durante el XIX la eclosión de las acciones mineras revertería en una nueva etapa del laboreo minero que ya había sido explotado en La Unión, Mazarrón y Águilas, siendo la base para la instalación de industrias afines destinadas a trabajar y tratar el mineral. Cartagena albergaría complejos destinados a la obtención de vidrio, cristal y loza, como ejemplificó la fábrica de la familia Valarino (1834). Y el sector agroalimentario, uno de los fundamentales del lugar debido a sus recursos naturales, diversificaría la obtención de vino, aceite y harina con la del pimentón abriendo una nueva etapa industrial que sería continuada en el siglo siguiente.

Un siglo donde los conflictos bélicos, la política nacional, las injerencias internacionales y sus propias carencias para afrontar cuestiones tan esenciales como disponer de fuentes energéticas, harían que la industria regional se viera forzada a mudarse y adaptarse, así como hacer frente a ciclos críticos que le afectaron considerablemente. El textil con el curtido de Lorca y el esparto en Cieza serían materias primas que dotarían de esencia industrial a estos municipios. La industria agroalimentaria continuaría con la estela iniciada sumando la conserva vegetal que irradiaría con fuerza tras elegir Alcantarilla los Esteva Canet para asentar su fábrica en la península. A la par la obtención de bebidas alcohólicas comenzó a ganar partido tanto con la activación de cerveceras, como fueron la extinguida "El Azor" (Cartagena, 1958), auspiciada por la marca "El Águila", y "Estrella de Levante" (Murcia, 1963), como con el desarrollo de destilerías tan significativas como "Bernal" (El Palmar, 1889) o "Licor 43" (Cartagena, 1945). Se reactivaría su industria vitivinícola, una de sus señas de identidad, asentada en Bullas, Jumilla y Yecla, 
donde también emergería la industria del mueble. Mientras que la actividad constructiva se nutriría de numerosas cerámicas distribuidas por todo su territorio. La minería seguiría siendo uno de sus activos y surgirían empresas destinadas a la obtención de envases, plásticos y cartonajes, esenciales para poner en el mercado los productos elaborados, así como otras destinadas a la fabricación de maquinaria. Además, se configuró uno de sus principales polos industriales: el Valle de Escombreras (Cartagena), sede de la industria energética y petroquímica.

Este breve resumen permite refrendar, en parte, la importancia industrial de este lugar y resaltar sus principales sectores industriales. En los años 80 los ajustes derivados de una nueva forma de entender las relaciones políticas, económicas, comerciales e industriales harían a la actividad industrial regional tener que reconvertirse y adaptarse a los nuevos tiempos. Esta situación provocó que la minería cesara por completo su actividad, se reajustaran sectores empresariales, como el agroalimentario, provocando el cierre de numerosos centros de trabajo o se apostara por nuevos modelos productivos que llevaban implícito el asentamiento en polígonos industriales que comenzaron a sacar a la industria de la ciudad. Ello acabaría generando una herencia industrial que vista bajo la perspectiva del patrimonio industrial incentivaba la necesidad de buscar medidas destinadas a recuperarla y ponerla en valor, cuestión que apoyada en el turismo permite ampliar su consideración (Pardo, 2004). Acción a la que también se sumaría a la industria en activo, siguiendo las líneas que se engloban dentro del turismo industrial.

\section{EL TURISMO COMO ALIADO DEL PATRIMONIO INDUSTRIAL}

El turismo es un activo económico que continuamente amplía sus fronteras con nuevos referentes y aspectos que lo diversifican, y configuran como un ente heterogéneo que de este modo atiende las diversas necesidades de un público que va mutando de gustos y parámetros de disfrute. Así, lo que antes pudiera considerase una cuestión anecdótica turísticamente, caso del turismo industrial, ha pasado a ser una tipología emergente del mismo donde se conjugan acciones referenciadas tanto en el patrimonio industrial, como en la industria en activo, pues en ambas cuestiones se asienta y sustenta (Caamaño, 2011: 162-163).

Esta forma turística, pese a que parece un fenómeno reciente, está vigente desde mediados del siglo XX, momento en el que a las visitas a industrias se convirtieron en una opción plausible en países como Francia. En paralelo el patrimonio industrial iba adquiriendo protagonismo como ente propio con diversas acciones que permitirían gestar museos sustentados en él. A la vez que se asentaba en Inglaterra una metodología propia para su estudio en la forma de la arqueología industrial (Hudson, 1966). Pasos que acabarían configurando un organismo que desde 1978 vela por él en la forma del "The International Committee for the Conservation of the Industrial Heritage" (TICCIH) y que revirtieron en un interés por sus referentes hasta llegar a ser incluidos en la Lista de Patrimonio Mundial de la UNESCO, siendo el primero de ellos las "Minas de Sal de Wieliczka" (Polonia, 1978). En combinación con estas acciones comenzó a generarse un corpus normativo donde a este patrimonio se sumaba el turismo como una iniciativa admisible para dotarlo de una nueva oportunidad que derivaría en su conservación y 
salvaguarda (Aguilar, 1998). Aspectos que también acabarían revirtiendo en la industria en activo, pues no en vano, había sido uno de los puntos que había permitido acercar lo industrial a la sociedad en su conjunto.

De este modo en la "Recomendación $n^{\circ} \mathrm{R}$ (87) 24 sobre las ciudades industriales europeas" (1987), se instó a impulsar medidas destinadas a reactivar, rehabilitar y aprovechar sus espacios industriales dada su adecuación para albergar nuevos usos con el fin de regenerar el sustrato industrial. Seguidamente en la "Recomendación n $n^{\circ}$ R (90) 20 relativa a la protección y a la conservación del patrimonio técnico, industrial y de obras de arte en Europa" (1991), se fijaron unas pautas destinadas a protegerlo y conservarlo, pero también se recogió la necesidad de incentivar en él el turismo cultural. Y en 1996, durante la celebración en Helsinki de la "IV Conferencia Europea de Ministros responsables del Patrimonio Cultural", de nuevo el turismo volvió a ser uno de los temas tratados con respecto a este patrimonio, ya que se abordó la necesidad de fomentar un turismo cultural sostenible, a través del cual se pudiera poner en valor la cultura europea y sus referentes, de donde participa el patrimonio técnico e industrial.

España activaría en 2001 su Plan Nacional de Patrimonio Industrial, impulsado por el "Instituto del Patrimonio Cultural de España", donde se definió como: "El resultado de una determinada relación social, la capitalista, y con un concreto sistema tecnológico, la mecanización. De esta forma sus manifestaciones quedaban comprendidas entre mediados del siglo XVIII y el último tercio del siglo XX, cuando se producen cambios sustanciales en la economía, en la tecnología y en los procesos productivos". Y se fijó que el turismo sería un punto a remarcar por dar una nueva oportunidad a los referentes enmarcados en él. Murcia participaría en esta acción incluyendo tres referentes industriales: el Arsenal de Cartagena, la Sierra Minera de Cartagena-La Unión y el embarcadero de mineral "El Hornillo" (Águilas)".

En el año 2003 el TICCIH presentaría la "Carta de Nizhny Tagil para el Patrimonio Industrial", donde tras varias definiciones y aportaciones de investigadores e instituciones de esta área, se daba la primera consolidada por el organismo que vela por él internacionalmente: "El patrimonio industrial se compone de los restos de la cultura industrial que poseen un valor histórico, tecnológico, social, arquitectónico o científico. Estos restos consisten en edificios y maquinaria, talleres, molinos y fábricas, minas y sitios para procesar y refinar, almacenes y depósitos, lugares donde se genera, se transmite y se usa energía, medios de transporte y toda su infraestructura, así como los sitios donde se desarrollan las actividades sociales relacionadas con la industria, tales como la vivienda, el culto religioso o la educación". El documento, esencial para entender lo qué es y actuar en el futuro sobre él, recogió un punto dedicado a su presentación e interpretación que trataba su cuestión turística. Sería aquí donde se remarcaría que precisaba para su conservación del interés y afecto del público, estos fueron los términos empleados, para ello era preciso que los poderes públicos lo mostrasen y explicasen a través de diversas herramientas y estrategias, entre las que se enumeraba el turismo. Junto a él se focalizaba la atención en los museos de la técnica y la industria, así como en los sitios industriales conservados al recalcar que resultaban esenciales

1 El Plan Nacional establecía la necesidad de declarar Bien de Interés Cultural (BIC) los bienes incluidos dentro del mismo que no tuvieran esta consideración. El Hornillo sería declarado BIC el 25/09/2009 (BORM 29/09/2009); la Sierra Minera lo lograría tras un largo y complejo proceso el 07/10/2015 (BORM 10/10/2015); y el Arsenal ha sufrido infructuosos intentos para ser incoado. 
para protegerlo y conservarlo, un aspecto que también refuerza la acción turística. Pero es que además aludía a las rutas, regionales e internacionales, protagonizadas por un común denominador industrial, pues a través de ellas era posible testimoniar la vinculación que existía entre los territorios y las personas que en ellos han habitado.

En 2004 y 2011 tendrían lugar en Zabrze (Polonia) dos conferencias internacionales sobre patrimonio industrial como recurso turístico y de ocio. En la primera se resaltó que este patrimonio era un referente valioso de la humanidad que debía ser considerado, a la vez que se indicó que los usos turísticos sobre el mismo debían de realizarse de manera coherente para legarlo al futuro de manera que se pudieran seguir apreciando sus valores. Para ello se articularon una serie de medidas a implementar sobre el mismo que se agruparon en cuatro bloques que iban desde el sector turístico, recopilando medidas para promoverlo; las autoridades públicas, necesarias para abordar las acciones al ser en la mayoría de los casos referentes que dependen de ellas; la investigación en este campo, donde se remarcó la necesidad de precisar las definiciones que lo enmarcarían de manera precisa y la normativa a aplicar; y por último, se resaltaba la relación que debía establecerse con la comunidad internacional puesto que era preciso converger de manera conjunta con entidades internacionales para reforzar las actuaciones emprendidas en este campo (Pardo, 2008: 63-68). En la segunda se fijó que su sustrato no era solo el patrimonio industrial, sino también los bienes y la inmaterialidad vinculadas también con las actividades productivas activas (Markua, 2011: 71-72).

A nivel nacional España revisaría y actualizaría el Plan Nacional en 2011. El nuevo texto aportaría una nueva definición del mismo: "Se entiende por patrimonio industrial el conjunto de los bienes muebles, inmuebles y sistemas de sociabilidad relacionados con la cultura del trabajo que han sido generados por las actividades de extracción, de transformación, de transporte, de distribución y gestión generadas por el sistema económico surgido de la "revolución industrial". Estos bienes se deben entender como un todo integral compuesto por el paisaje en el que se insertan, las relaciones industriales en que se estructuran, las arquitecturas que los caracteriza, las técnicas utilizadas en sus procedimientos, los archivos generados durante su actividad y sus prácticas de carácter simbólico". Y se daría mayor protagonismo al turismo pues fue una cuestión explícitamente remarcada, inicialmente para subrayar lo negativo que resulta cuando no se aborda de manera sostenible y responsable. Pero también para apuntar que es una oportunidad a tener en cuenta cuando se recopilan las propuestas a incentivar, pues una de ellas lleva por título: "Fomentar el turismo industrial y difundir ejemplos de regeneración de barrios o de territorios que hayan tenido un impacto positivo", indicando que puede ser un activo para el desarrollo local que es preciso divulgar y fomentar mostrando las acciones que han actuado de manera coherente y respetuosa con los referentes y que han tenido un efecto positivo para su territorio y sus habitantes. Murcia mantendría dentro del Plan sus tres referentes iniciales, sumando el Coto Minero San Cristóbal-Los Perules de Mazarrón² (Biel, Cueto, 2011: 262-269).

Ese mismo año se celebraría la " $17^{\mathrm{a}}$ Asamblea General del Consejo Internacional de Monumentos y Sitios" (ICOMOS) que recopilaría en un documento los "Principios conjuntos de ICOMOS-TICCIH para la conservación de sitios, conjuntos, áreas y paisajes del

2 Este coto minero fue declarado BIC el 26/09/2008 (BORM 15/10/2008). Posteriormente hubo que corregir un error en las coordenadas (BORM 26/06/2014). 
patrimonio industrial", donde no se aludiría de una manera expresa al turismo, pero sí que en su último punto indicaría que para que fuera valorado por la sociedad contemporánea era prioritario incentivar su conocimiento, aspecto en donde el acceso a él resultaba el mejor aliado en la forma de visitas, museos, exposiciones e itinerarios.

En paralelo a estas medidas surgían los itinerarios culturales impulsados por el Consejo de Europa, donde hierro, olivo, vino y cerámica conformarían los industriales dentro de su opción. Mientras se activaba la "European Route of Industrial Heritage" (ERIH), un baluarte para la proyección del turismo industrial al proceder a señalar una serie de referentes de este tipo representativos de Europa. Esta iniciativa sería imitada ya con el apelativo de turismo, para crear una entidad menor de la misma, como ocurriría en España con la "Red Española de Turismo Industrial" (RETI) presentada en 2013 con la intención de cohesionar esfuerzos para inducir esta actividad, y que en parte seguía el modelo que ya venía desarrollando en Cataluña "Xarxa de Turisme Industrial de Catalunya" (XATIC) y la "Cámara de Comercio de Toledo", pioneras en la promoción de esta acción en nuestro país.

Este aspecto se reforzaría en España con la norma UNE 302001 destinada a regularizar y fijar los servicios que deben reunir las entidades que potencien actividades turísticas industriales. Impulsada por el "Instituto para la Calidad Turística Española", fue promulgada en 2012 con el fin de regularizar y fijar los servicios que deben reunir las entidades que potencien actividades turísticas industriales, tanto las basadas en patrimonio industrial como en industria viva. Quienes cumplan con los requisitos de la misma pueden optar a obtener la "Marca Q", la referencia que reseña la calidad turística española y que es significado de actividad prestigiosa, diferenciable, fiable, rigurosa y que supone un activo importante para su promoción (Portela, Martínez, Guillén, 2015).

Estas disposiciones han permitido a los referentes industriales pretéritos y actuales, en uso o en desuso, patrimonializados o vivos, convertirse en una opción turística sólida apostando por un modelo único o por la conjugación de varias iniciativas. Diversas opciones que testimonian las variables del turismo industrial y que ejemplifica la Región de Murcia.

\section{EL TURISMO INDUSTRIAL EN LA REGIÓN DE MURCIA: UNA INCIATIVA EN MARCHA}

El turismo conforma un pilar de la economía regional, que si bien comenzó apoyándose en la fórmula de "sol y playa", paulatinamente ha ido completando y aumentando su radio de acción a través del turismo cultural. Sería precisamente bajo este prisma sobre el que se comenzarían a verse sus elementos industriales. De este modo, en 2012, se inició un plan activado por la "Consejería de Industria, Empresa e Innovación" del Gobierno Regional para promover el turismo industrial, abogando así por ampliar la oferta que había hasta entonces a través de la activación de rutas, generar focos de industria viva susceptibles de participar de esta vertiente e implementar la difusión de su sustrato patrimonial ${ }^{3}$, así se quería impulsar una propuesta que ya había comenzado a desarrollarse con anterioridad.

3 Diario La Opinión. Noticia 30/11/2011 [Disponible en http://www.laopiniondemurcia.es/comunidad/2011/11/30/disena-turismo-industrial-sacarle-partido-viejas-fabricas/367875.html]. Consulta: 25/02/2016. En 2014 la Región de Murcia participaría en el "5º Congreso Europeo de Turismo Industrial", presentando 


\subsection{Museos y rutas de la industria regional: Opción turística por potenciar}

Los museos, como entes destinados a la custodia, exposición y difusión del patrimonio cultural, fueron el primer recurso turístico que se implantó, siguiendo la tónica nacional de musealizar lo patrimonial. En ellos predomina más que una visión particular sobre este sustrato, una fusión con lo técnico-científico, que permite vincular sus aportaciones con el desarrollo industrial y lo etnográfico para facilitar así su conexión con lo artesanal, aunque en algunos casos la unión de ambos no termina de darse. Esta proyección deriva en que el solapamiento de vertientes repercuta en la conjugación de demasiados elementos que obstaculizan la lectura de la proyección industrial que se quiere remarcar. En otros casos abordan un sector industrial de forma monográfica, como ocurre con los mineros y vinícolas. También los hay específicos para los medios de transporte, focalizados en el ferrocarril con una incursión en la aeronáutica, y los militares, relacionados con sus sustratos militar y naval.

Un aspecto a destacar es el espacio en el que se alojan porque una parte se asienta en los lugares donde se desarrollaron las actividades que enmarcan. Es el caso del "Parque Minero de La Unión", que ofrece la posibilidad de adentrarse en una explotación minera de pirita y recorrer las instalaciones que se empleaban para el laboreo de mineral en un complejo ubicado dentro de la propia Sierra Minera (Manteca, García, 2005). Mientras que el centro de interpretación de la mina "Las Matildes" se ubica sobre sus espacios mineros rehabilitados. En los túneles del "Hornillo" se ha conformado uno focalizado en él. Los del vino se sitúan en bodegas tradicionales recuperadas, aspecto que se repite en el centrado en la luz ocupando la antigua fábrica que la generaba, como ocurre con la almazara de Pliego o el conjunto molinero hidráulico de Murcia. Diferente es el ejemplo de la antigua fábrica de salazones de época romana, alejada del marco cronológico que el Plan Nacional da para enmarcar el patrimonio industrial, donde ella es el inmueble que custodia un legado arqueológico que contiene sus secciones más características demostrando la larga historia de una actividad que desde entonces estaría vinculada a la Región de Murcia.

Esta oferta se ha visto completada con la activación de una serie de rutas que se han centrado de nuevo, como en el caso de los museos, en el sector agroalimentario y minero. Aquí destacan las tres rutas etnoturísticas focalizadas en el vino que se desarrollan por los municipios regionales que disponen de una denominación de origen propia en esta rama, como son Jumilla, Bullas y Yecla (Elías, 2006). Estas rutas están adheridas al proyecto elaborado por la "Asociación Española de Ciudades del Vino", en donde se han contado con la implicación de los ministerios de "Industria, Energía y Turismo" y de "Agricultura, Alimentación y Medio Ambiente", con la intención de crear un producto turístico de calidad que focalizara la atención en este referente de la cultura española. A través de esta iniciativa se ha impulsado la creación de rutas del vino que aglutinan las vertientes del turismo industrial: referentes patrimoniales y bodegas en activo, junto con el paisaje que generan los viñedos y los elementos culturales y patrimoniales propios de estos municipios con un marco cronológico que abarca varios períodos históricos.

las propuestas que dentro de este marco ofrecían municipios como La Unión, Águilas, Mazarrón, Molina de Segura y Cartagena. Diario La Verdad. Noticia 23/06/2014 [Disponible en http:/www.laverdad.es/murcia/ turismo/201406/23/region-busca-hacerse-hueco-20140623011803-v.html]. Consulta: 25/02/2016. 


\section{Tabla 1 \\ MUNICIPIOS Y MUSEOS DE CARÁCTER CIENTÍFICO-TÉCNICO E INDUSTRIAL EN LA REGIÓN DE MURCIA}

\begin{tabular}{|c|c|c|c|}
\hline Munieipio & Museo & Sector & Referentes \\
\hline Águilas & Museo del Ferrocarril & Transporte & Medios de transporte \\
\hline Águilas & Museo del Hornillo & Transporte & $\begin{array}{l}\text { Medios de transporte, } \\
\text { industrial }\end{array}$ \\
\hline Archena & Museo del Esparto & Textil & Etnográficos e industriales \\
\hline Blanca & $\begin{array}{l}\text { Centro de Interpretación de la } \\
\text { Luz y el Agua }\end{array}$ & Energía & Técnicos \\
\hline Bullas & Museo del Vino & Agroalimentario & Etnográficos e industriales \\
\hline Bullas & Casa-Museo Don Pepe Marsilla & Agroalimentario & Etnográficos \\
\hline Calasparra & Museo del Arroz & Agroalimentario & Etnográficos e industriales \\
\hline Cartagena & Museo Naval & Naval & Técnicos y navales \\
\hline Cartagena & Museo Histórico Militar & - & Técnicos y militares \\
\hline Ceutí & $\begin{array}{l}\text { Museo de la Conserva Vegetal } \\
\text { y las Costumbres: Siete } \\
\text { Chimeneas }\end{array}$ & Agroalimentario & Etnográficos e industriales \\
\hline Cieza & $\begin{array}{l}\text { Centro de Interpretación del } \\
\text { Esparto y su Industria }\end{array}$ & Textil & Etnográficos e industriales \\
\hline Cieza & $\begin{array}{l}\text { Museo Hidráulico Molino de } \\
\text { Teodoro }\end{array}$ & Agroalimentario & Etnográficos \\
\hline Jumilla & Museo del Vino Juan Carcelén & Agroalimentario & Etnográficos e industriales \\
\hline La Unión & Museo Minero & Minería & Industriales \\
\hline La Unión & Parque Minero de La Unión & Minería & Industriales \\
\hline La Unión & $\begin{array}{l}\text { Centro de Interpretación "Mina } \\
\text { Las Matildes" }\end{array}$ & Minería & Industriales \\
\hline Los Alcázares & Museo Aeronáutico Municipal & Transporte & Medios de transporte \\
\hline Mazarrón & $\begin{array}{l}\text { Museo arqueológico "Factoría } \\
\text { Romana de Salazones" }\end{array}$ & Agroalimentario & Arqueológicos \\
\hline Molina de Segura & $\begin{array}{l}\text { Museo Etnográfico Carlos } \\
\text { Soriano }\end{array}$ & Agroalimentario & Etnográficos e industriales \\
\hline Murcia & Museo de la Ciencia y el Agua & - & Científicos y técnicos \\
\hline Murcia & $\begin{array}{l}\text { Museo Hidráulico "Los } \\
\text { Molinos del Río Segura" }\end{array}$ & Energía-Agroalimentario & Etnográficos e industriales \\
\hline Murcia & Museo Ferroviario & Transporte & Medios de transporte \\
\hline Pliego & $\begin{array}{l}\text { Museo de la Almazara } \\
\text { Santiaguista }\end{array}$ & Agroalimentario & Etnográficos \\
\hline
\end{tabular}

Fuente: elaboración propia.

Un carácter diferente tiene la "Ruta del 33" (La Unión), cuyo protagonismo se centra en el patrimonio minero y el paisaje industrial vinculado a esta vía que toma como referencia el antiguo camino del mismo nombre que nació con la pretensión de unir La Unión y Portmán, discurriendo por las entrañas de la Sierra Minera. Por su ubicación en 
un espacio agreste se ha convertido en un referente para realizar rutas con bicicleta de montaña, siendo también un activo para el turismo deportivo y de aventura, al margen del industrial (Manteca, García, Ródenas, 1999).

Tabla 2

RELACIÓN DE RUTAS INDUSTRIALES EN LA REGIÓN DE MURCIA

\begin{tabular}{|lll|}
\hline Municipio & Denominación & Sector \\
\hline Águilas & Ruta del embarcadero del "Hornillo" & Minero-Medios de transporte \\
\hline Águilas & Ruta del ferrocarril & Medios de trasporte \\
\hline Bullas & Ruta del vino & Agroalimentario \\
\hline Jumilla & Ruta del vino & Agroalimentario \\
\hline La Unión & Ruta del 33 & Minero \\
\hline Molina de Segura & Entre chimeneas & Agroalimentario-Construcción \\
\hline Yecla & Ruta del vino & Agroalimentario \\
\hline
\end{tabular}

Fuente: elaboración propia.

Diferentes, por discurrir dentro del espacio urbano, son otras rutas, como la denominada "Entre Chimeneas" (Molina de Segura), la cual tiene como eje vertebrador las chimeneas industriales que quedan del pasado conservero y cerámico de la esta localidad, hoy convertidas en adornos verticales ubicadas en las plazas que han surgido en los espacios que antes ocupaban sus instalaciones industriales. Aquí los referentes son mínimos y repetitivos, motivo por el cual se ha reforzado con la inclusión de las esculturas contemporáneas con las que comparten espacio. Como las que en Águilas se han articulado sobre su sustrato ferroviario y minero, unificando los principales referentes que dan cuenta del mismo teniendo como ítem principal el embarcadero del "Hornillo", con sus propias instalaciones (puente, estación, vías, túneles, tolvas), hasta los museos y espacios expositivos que remarcan la importancia que el tren tuvo en esta localidad, nexo de unión ferroviaria con Andalucía, lugar de salida del mineral del sureste y sede de uno de los talleres de la empresa RENFE ${ }^{4}$.

Murcia también dispone de una vía verde, una actuación que promueve desde 1993 la "Fundación de los Ferrocarriles Españoles", quien a través de la "Gerencia de Vías Verdes y Medio Ambiente" trabaja en la recuperación de vías de ferrocarril sin uso con fines culturales, naturales y paisajísticos. Quizás el apelativo de verde y la consideración natural que parece predominar en su activación hace que a veces se pierda de vista que realmente estas vías se sustentan en un referente vinculado al transporte de personas y mercancías. Y es que el ferrocarril es un testimonio de la capacidad de superación del

4 Dentro del plan regional para activar el turismo industrial se remarcó la ruta "Descubriendo Alcantari1la", municipio protagonista de la eclosión de la industria conservera regional, sin embargo, no se ha encontrado información sobre la misma en la actualidad. Diario La Verdad. Noticia 24/06/2013 [Disponible en http://www. laverdad.es/murcia/v/20130624/region/region-aspira-referente-nacional-20130624.html]. Consulta: 12/12/2015. Recientemente los medios regionales han recogido la propuesta de unir el patrimonio minero de la Sierra Minera con el sustrato paleontológico de la cueva Victoria y el monasterio de San Ginés de la Jara en una ruta. Diario La Verdad. Noticia 22/10/2015 [Disponible en http://www.laverdad.es/murcia/cartagena/201510/22/ruta-minerajunto-menor-20151022013858-v.html]. Consulta: 24/02/2016. 
hombre por buscar medios de transporte, algo que sin lugar a dudas queda lejos del discurso que se quiere transmitir ahora como espacio que rescata un paisaje. En concreto la recobrada aquí es la "Vía Verde del Noroeste" (1998), que se sustenta sobre la línea que unía Caravaca y Murcia en un trayecto de 76,8 kilómetros a través del cual se suman diversos municipios que ofrecen la oportunidad de conocer tanto su patrimonio cultural, como el natural y el ligado a la propia vía en la forma de sus estaciones, apeaderos, túneles y viaductos, motivándose el acceso a pie como mediante medios de transporte sostenibles y respetuosos con el medio ambiente, caso de la bicicleta. Su activación ha llevado aparejada la intervención en parte de sus bienes inmuebles que han permitido a los mismos poder desempeñar otras tareas, como convertirse en albergues o alojar negocios de hostelería (Conesa, 2000).

\section{Mapa 1 \\ UBICACIÓN DE MUSEOS Y RUTAS DE CARÁCTER INDUSTRIAL EN LA REGIÓN DE MURCIA}
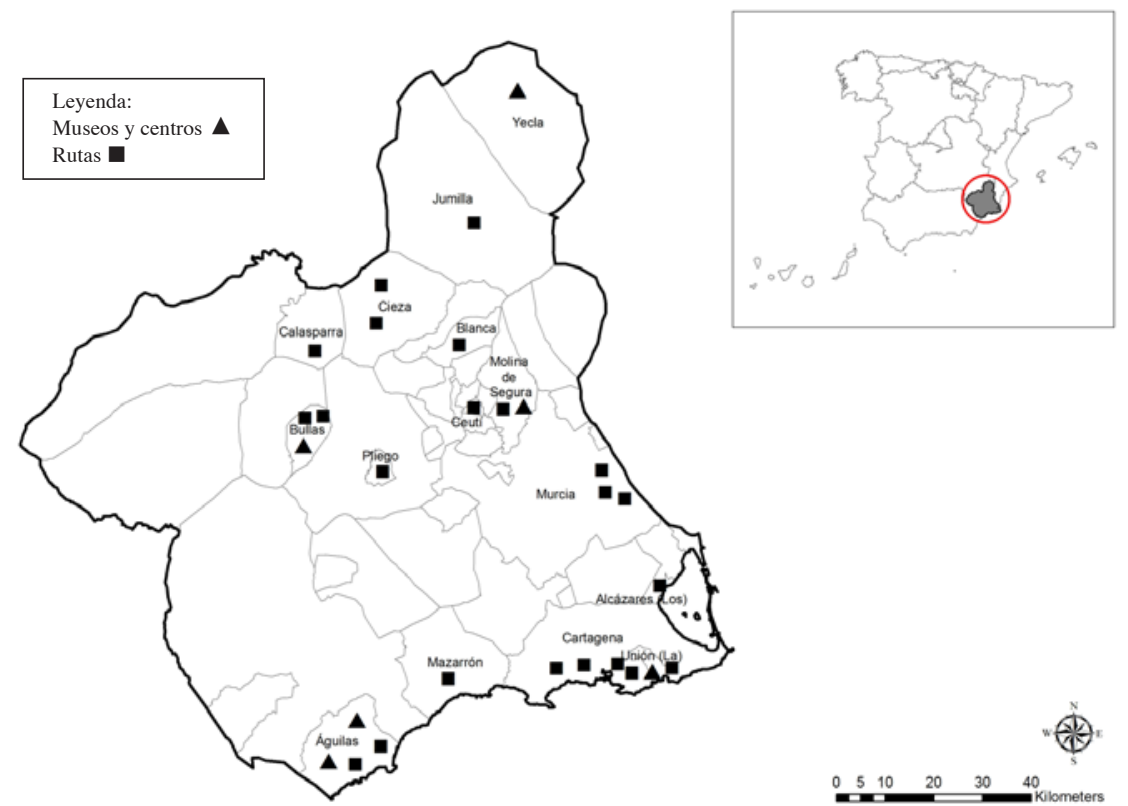

Fuente: elaboración propia.

La proyección de estas propuestas no nos debe hacer perder de vista su realidad. Se trata de iniciativas de corte local, salvo en el caso del parque minero, el cual se ha conformado como un producto turístico gestionado por una empresa privada ${ }^{5}$, que tienen

5 Pero su importancia no solo estriba en este aspecto, sino también en la proyección que se ha hecho de él puesto que incluso desde antes de su apertura en 2010, se convertiría en un referente señero para los intereses turísticos de Murcia quien lo empleó como parte de su promoción turística en la "Feria Internacional de Turismo" 
escasa trascendencia más allá de su radio de acción. Difundir las mismas es, a menudo, un ejercicio de obstáculos dado que no participan de los canales fijados, ni tienen capacidad para asumir la misma dada su entidad, pese a ello sus promotores, corporaciones locales y asociaciones, realizan un importante esfuerzo por mantener su presencia en los medios regionales. De todos los museos solo los del vino de Bullas, el minero de La Unión y el arqueológico de Mazarrón, forman parte del "Sistema Regional de Museos", a través del cual se articulan medidas de colaboración y cooperación entre los que lo conforman, veintidós actualmente, promoviendo acciones de difusión de manera conjunta. El resto no participa de este sistema pero sí se encuentran en el portal regional "Región de Murcia Digital" y en la web oficial de turismo de Murcia.

El acceso a las rutas es más complicado dado que se articulan desde los municipios que las enmarcan y las publicitan en sus propios canales, no yendo más allá de su territorio en algunos casos. Aspectos a los que se añade un horario de visita variable y en ocasiones incompatible con las preferencias de sus visitantes, así como con un personal no formado específicamente en el área industrial y la falta de información directa sobre las rutas en la forma de señales y paneles informativos adecuados. Algo que es contrarrestado con el impulso de actividades, ajustadas a sus condiciones, para atraer público aunque no siempre repercuten de manera favorable al pasar desapercibidas. Por último, conviene destacar que los sectores que se han focalizado la atención de estas propuestas se asientan sobre pilares de la economía regional, estando encabezados por el sector agroalimentario, seguido de los medios de transporte y la minería, quedando el resto en un nivel inferior, cuestión que realmente no ejemplifica la importancia de los mismos.

\section{Gráfico 1 \\ PORCENTAJE DE ACTUACIONES POR SECTORES}

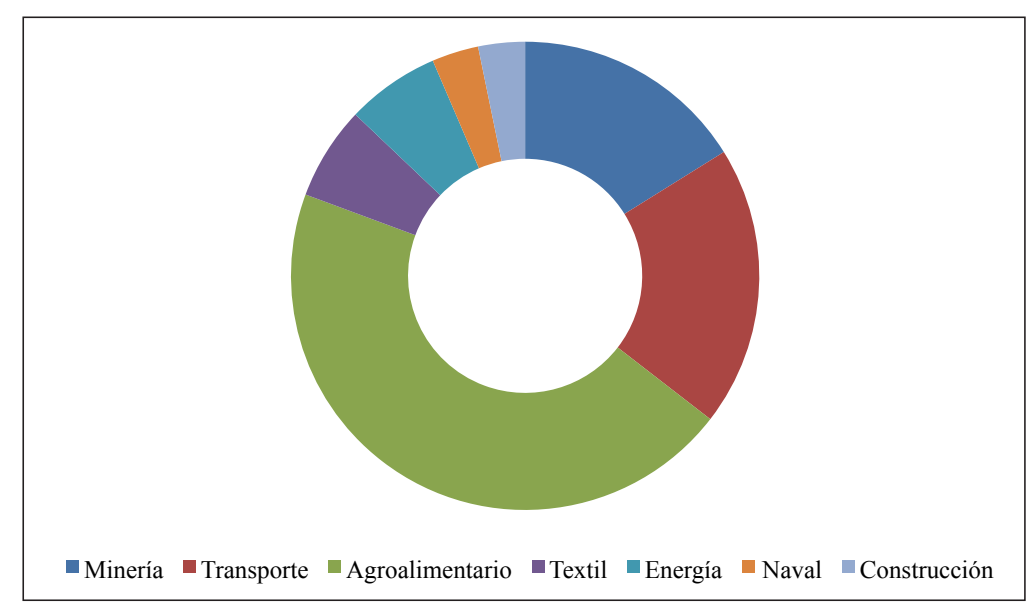

Fuente: elaboración propia.

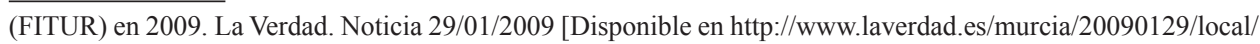
region/rehabilitacion-mina-grande-espana-200901291252.html]. Consulta: 26/02/2016. 


\subsection{La empresa activa como turismo: Vertiente en expansión}

La vertiente activa del turismo industrial está implantada en la industria regional mediante las visitas que periódicamente se pueden realizar a diversos centros de trabajo. Lo que ocurre es que no se disponen de mecanismos para formular de manera adecuada esta opción, es decir, mostrar los centros que se pueden visitar y articular medidas para gestionar las mismas. Precisamente para cubrir esta parcela ha surgido una empresa: "Turinde. Visita a Industrias y Empresas", especializada en turismo industrial, preferentemente en su vertiente activa, aunque también actúa sobre el patrimonial. Ella opera como intermediaria para cohesionar empresas y visitantes. Pero no se limita a este aspecto ya que abarca la consultoría especializada en esta materia de acuerdo con la norma UNE 302001 de turismo industrial; tiene capacidad para llevar a cabo el estudio, análisis y elaboración de planes para poder realizar visitas en las empresas, así como para realizar vídeos explicativos; sumando a ello un servicio de guías, la gestión de la difusión y promoción de la actividad y encargarse del traslado de los visitantes ${ }^{6}$. Mientras, desde una vertiente pública, Murcia participa en la RETI, a través de la cual se logra visualizar las industrias que participan de este proceso y conectar a los interesados en esta propuesta, así como difundir esta iniciativa más allá de las fronteras locales y regionales que hasta este momento limitaban la promoción de esta medida.

Con la conjugación de estas acciones es posible lograr promocionar esta opción a todos los niveles (regionales, nacionales e internacionales), así como dar visibilidad a una propuesta turística que hasta entonces era opaca pese a que existía y era posible ejercitarla. Otro punto a tener en cuenta es que frente a los museos y rutas, no solo actúa sobre elementos vivos, en uso, sino que además lo hace sobre referentes privados que dependen de las empresas y no únicamente del ente público, un aspecto significativo que conviene tener en cuenta porque su gestión y motivaciones son totalmente diferentes. Y es que ese aspecto es quizás el más problemático: no es fácil conjugar la actividad diaria de los centros de trabajo con la turística, la necesidad de adoptar medidas de seguridad, evitar incomodidades a los obreros y sortear el espionaje de posibles competidores se esgrimen como elementos que coartan el desarrollo de esta vertiente, pero lo cierto es que mediante su desarrollo es posible reforzar su imagen externa, reconocer la labor de la empresa y aumentar, mediante la venta de productos, sus ingresos. Por eso es una opción que va ganando terreno, aunque sea de manera paulatina (Caamaño, 2011: 168-173).

\section{NUEVAS OPCIONES PARA ACTIVAR EL TURISMO INDUSTRIAL EN LA REGIÓN DE MURCIA}

Pese a todo lo realizado si se quiere impulsar esta opción turística es necesario visualizar lo acometido, subsanando los aspectos negativos relativos a falta de difusión y proyección, a la par que incentivar nuevas propuestas que tengan entre sus objetivos prioritarios la propagación, el respeto y la consolidación del sustrato industrial pasado y presente de la Región de Murcia. Para ello lo primero es abordar el conocimiento de su legado industrial

\footnotetext{
6 Esta empresa organizó en 2015 la "I Jornada de Turismo Industrial-Región de Murcia".
} 
de manera exhaustiva, de este modo se remarcaría lo susceptible de pasar a protagonizar iniciativas turísticas, un punto en donde se hace necesaria la participación no solo de expertos en turismo, sino también de la del resto de disciplinas que participan del estudio del ámbito industrial (historia, economía, sociología, arquitectura, paisaje, documentación, etc.) ya que es complejo conocerlo en profundidad al ser un campo en el que convergen diversas áreas, cuya conexión permitiría resaltar e impulsar nuevas propuestas que diversificarán y ampliarán lo realizado buscando dar más protagonismo a la fusión entre patrimonio industrial e industria en activo y generar conexiones con otras áreas geográficas.

\subsection{Conjugación de variantes del turismo industrial: Diversas opciones}

Entre las propuestas que apuntamos destaca la creación de un hilo argumental a partir de la obtención de electricidad recurriendo a instalaciones en activo. Murcia atesora un importante número de fábricas de luz en la zona del Valle de Ricote, donde se fusionan con un marco natural de gran singularidad gestado por el río Segura cuya fuerza hídrica atrajo estas instalaciones a sus orillas (Griñán, Palazón, 2013). La incidencia de estas instalaciones en este territorio ha derivado en que en Blanca su antigua instalación se haya convertido en un museo, donde es posible seguir la historia de esta instalación de forma tradicional: máquinas paradas y paneles expositivos, sin lograr transmitir la realidad de este tipo de instalaciones. Algo que sin embargo ofrecen municipios próximos: Abarán, Ulea, Ojós o Archena, donde todavía se mantienen instalaciones en buen estado de conservación y en uso de similares rasgos a la musealizada que permitirían conocer directamente cómo se obtiene la luz a través del agua, una experiencia sin lugar a duda más dinámica y que haría de la realidad un atractivo aprovechando el auge que hay en la actualidad por las energías renovables. Pero no solo ellas serían foco de atención: la ubicación de plantas energéticas en el Valle de Escombreras (Cartagena) o de paneles solares en los municipios regionales, serían un aliado para conocer las implicaciones de estas instalaciones y ser conscientes de la evolución en la obtención de un elemento esencial para el desarrollo de cualquier actividad.

Es indiscutible que la minería es una de las grandes protagonistas del turismo industrial regional. Pero hasta el momento las actuaciones se han centrado en el radio de acción de la Sierra Minera (La Unión-Cartagena). Es incuestionable minimizar su importancia pero es cierto que se cuentan con otros lugares donde el trasfondo de esta actividad quedó latente, como testimonian los municipios de Águilas, Lorca o Mazarrón, con sus cotos de San Cristóbal y Los Perules, Pedreras Viejas y Fortuna sobre los cuales no se ha abordado ninguna medida, al margen de las visitas guiadas que facilita el ayuntamiento. Si bien es cierto que desde la administración regional y local se ha planteado la posibilidad de crear en Mazarrón un nuevo parque minero a semejanza del modelo implantado en La Unión habiéndose llegado a crear incluso un consorcio turístico para impulsarlo, propuesta que la coyuntura económica relegaría. Esta propuesta hubiera supuesto la combinación de dos formatos similares en una comunidad pequeña donde sería recomendable diversificar y no repetir, motivo por el cual quizás se podría apostar por hacer a este espacio protagonista de otras actividades, entre las que podrían destacar las deportivas o de aventura (espeleología, rutas a campo a través, en bici, etc.) debido a las características de su terreno y a las oportunidades que ofrece para su puesta en marcha. 
Como hemos apuntado la agroalimentaria fue, y es un sector, esencial para la economía regional y en donde, pese a lo realizado, se pueden abordar nuevos capítulos que potencien el conocimiento de sectores que han quedado alejados de las acciones propuestas, especialmente su sustrato conservero. Sus vestigios son latentes en el territorio al disponer de numerosos municipios donde esta actividad se asentó con fuerza, siendo además originadora de otras instalaciones auxiliares que precisaba para desarrollarse de manera correcta (cartonaje, envases, plásticos, transportes). Hace años que el ayuntamiento de Villanueva del Río Segura quiso convertir la factoría de Cayetano Ayala Guillén en un museo de la industria conservera, pero no llegaría a materializarse. La ubicación de estos centros laborales en los cascos urbanos ha derivado en que su cierre lleve aparejado la sustitución de los mismos por espacios residenciales en los que, en el mejor de los casos, ha quedado su chimenea industrial. Claramente una sucesión de chimeneas no es un reclamo turístico, ni siquiera un activo patrimonial considerable cuando solo se mantienen por entender que por sí mismas son representativas de lo que allí hubo y ello coincida con que son lo que menos espacio ocupa en planta curiosamente. Pero apostar por la creación de un centro de interpretación o museo y fijar una ruta con sus principales referentes, ofrecer la posibilidad de conocer por dentro alguna de las conserveras que todavía se mantienen en la región, unirla con los sectores afines y sumar a todo ello el acceso y conocimiento de los huertos donde se cultivan los productos que luego serán transformados en conservas y mermeladas, puede ser una opción a tener en cuenta (Griñán, López, Palazón, 2008). Lo mismo podríamos decir de las instalaciones dedicadas a la obtención de pimentón, cuyo sustrato físico ha sido minimizado por el progreso del tiempo, y de las harineras, esenciales para entender la evolución industrial de Murcia, de las cuales se cuentan con centros de transformación de diversas épocas y que en el caso de "La Constancia" (Murcia) 7 llegó a plantearse la posibilidad de asentar en ella un museo aprovechando que custodiaba parte de su maquinaria, iniciativa que tampoco se realizaría.

Entre la industria extractiva y la agroalimentaria se sitúa la sal, un recurso que abunda en este territorio con salinas de interior y marinas, parte de las cuales se encuentran en mal estado y abandonadas, peligrando su mantenimiento a corto plazo pese a ser también un foco de sostenibilidad natural por sus implicaciones medioambientales. En ellas las tareas que permiten la obtención de este elemento no se desarrollan siguiendo un patrón productivo industrial al uso, sino que se rigen por un ciclo natural que deriva en que el agua dé paso a la sal lo que permite ver la evolución del proceso durante su obtención en sus diversas fases, de modo que cada visita ofrecería un momento concreto, facilitando así el interés por ver el resto en otras visitas. Pero no únicamente se podría actuar sobre la obtención de sal, sino también sobre su uso en procesos industriales tan importantes como es la industria del salazón explicando su trayectoria histórica conjugada con las visitas a instalaciones de este tipo. Ello permitiría conectar la sal con las aplicaciones gastronómicas, naturales, culturales y termales del lugar. De este modo sería posible articular varias iniciativas e impulsar las que ya están en activo, especialmente en las zonas costeras, destacando las que protagonizan las salinas y arenales de San Pedro del Pinatar logrando así optimizar y diversificar recursos.

7 Se trata de una fábrica de harinas ubicada en el centro histórico de la ciudad de Murcia, habiendo sido el primer referente industrial regional que obtuvo la categoría de BIC en 1992. 


\section{Cuadro imágenes 1 \\ INSTALACIONES INDUSTRIALES}

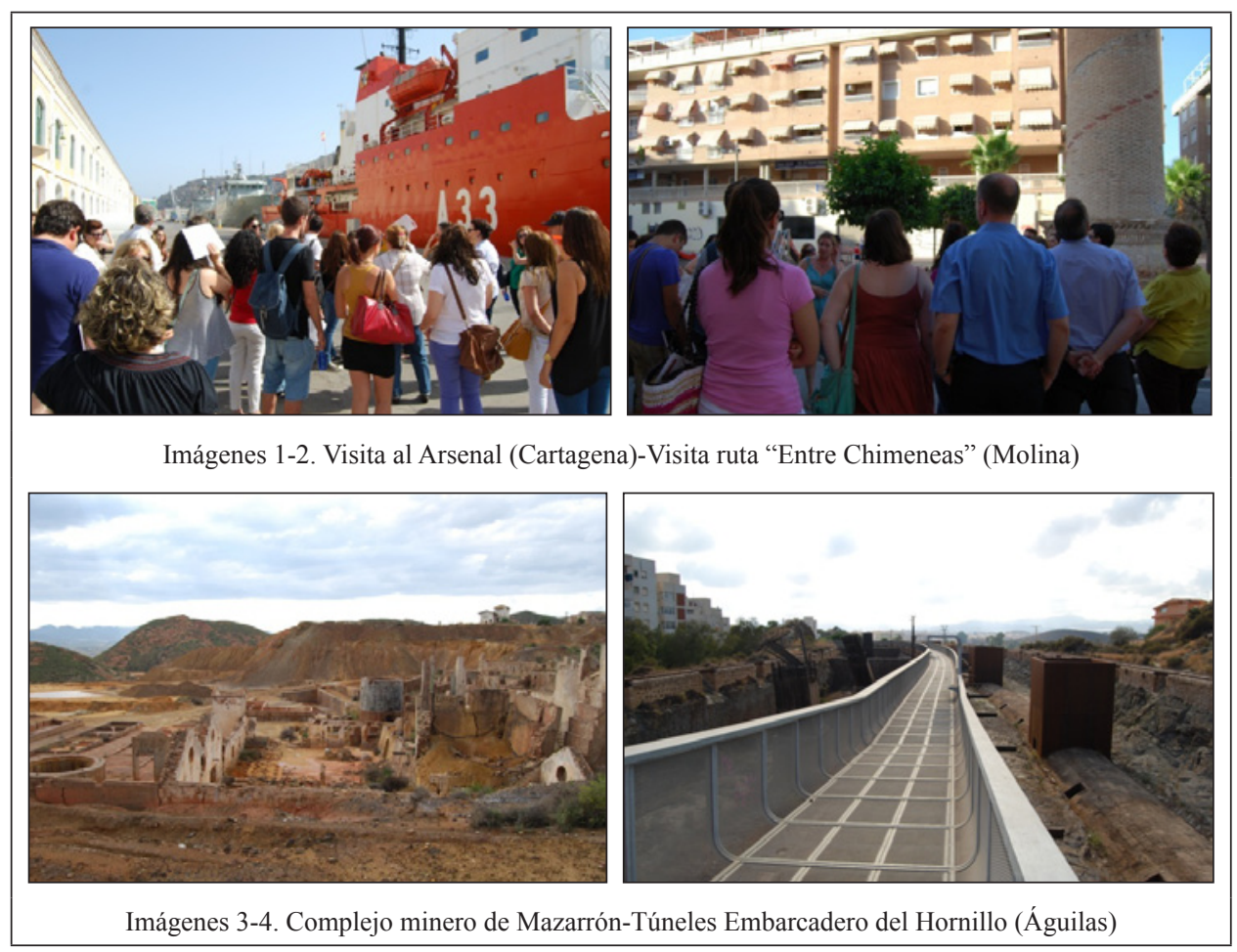

Fuente: elaboración propia.

El textil ha sido una seña de identidad de la industria regional que va mas allá de la alusión histórica a la seda, de la que quedan referentes museísticos en sus museos etnográficos y perviven tenues referencias físicas en la ciudad de Murcia: la chimenea de una de sus fábricas en el "Jardín de la Seda", en pleno barrio de San Antón; el denominado "Palacete de la Seda" (Santa Cruz), aunque fuera por poco tiempo una instalación sedera; la antigua portada del "Contraste de la Seda", hoy acceso de una sala de exposiciones del "Museo de Bellas Artes de Murcia"; y la entrada del "Colegio de la Anunciata", posteriormente "Fábrica de Seda a la Piamontesa" que sería adoptada como puerta a un restaurante ubicado en la "Casa de los Nueve Pisos". Todo ello testimonia una actividad que pese a sus mínimos actuales tuvo una proyección máxima en el pasado. Lo mismo ocurre con los paños de Caravaca, el curtido en Lorca, todavía en activo, o el esparto, que sí cuenta con un centro de interpretación en Cieza que ha pasado a sustituir su primigenio museo. Darle una mayor visibilidad a estos referentes e impulsar reseñas correctas sobre sus vestigios, junto con una inclusión en los mapas turísticos, aliados de visitantes y turistas, permitirían rescatarlos del anonimato en el que se encuentran y potenciar su difusión. 


\section{Cuadro imágenes 2 MUSEOS INDUSTRIALES}
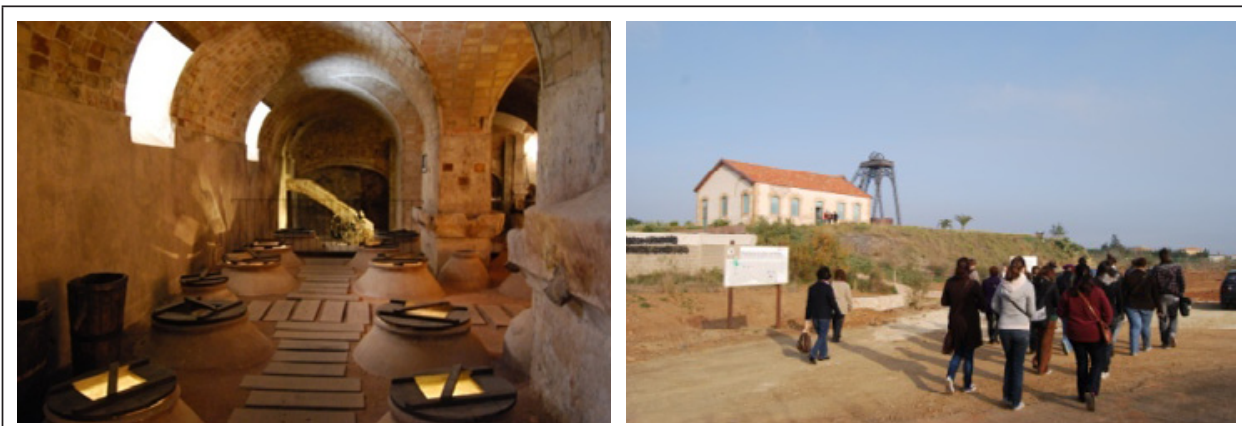

Imágenes 5-6. Museo del Vino (Bullas)-Centro de Interpretación Mina “Las Matildes” (La Unión)
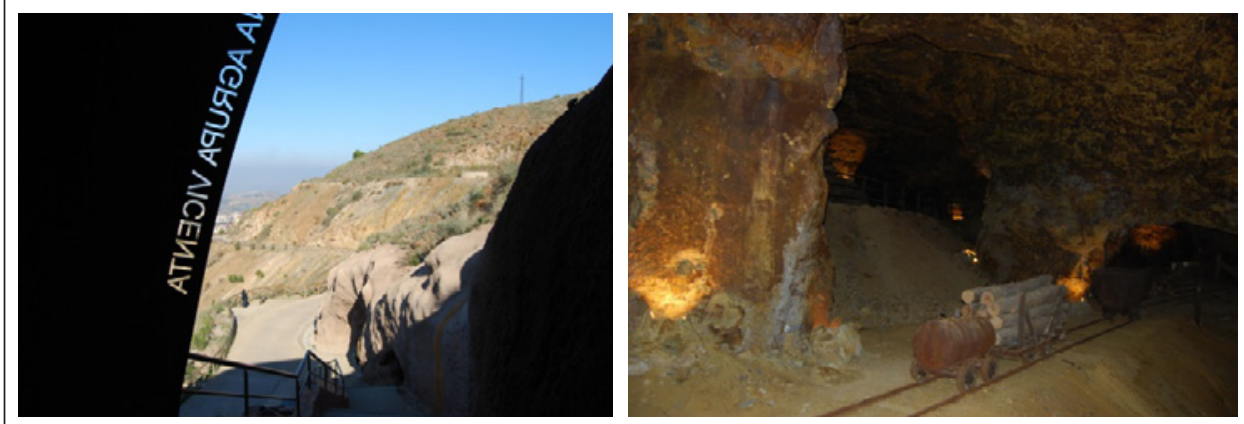

Imágenes 7-8. Parque Minero “Agrupa Vicenta” (La Unión)

Fuente: elaboración propia.

En otro rango se encuentran otra serie de industrias vitales para el desarrollo naval y militar de nuestro país. Y es que la Región de Murcia fue escogida para ubicar tanto un "Arsenal" (Cartagena), con funciones navales, militares y defensivas, que todavía se mantiene activo, estando su parte naval en manos de la empresa "Navantia"; como una "Real Fábrica de Pólvora" (Javalí Viejo), en funcionamiento desde sus inicios; y dos fábricas de salitre, material necesario para la obtención de pólvora, una en Murcia, que pervive en parte en un estado lamentable y que podía ser el contenedor apropiado para reunir parte de los vestigios industriales regionales, y otra en Lorca, totalmente desmantelada y de la que quedan unas columnas que adoran diversos espacios de la ciudad. Pues bien pese a ello, salvo el centro de Cartagena, el resto no tienen todavía articulada ninguna medida para potenciar su conocimiento y disfrute. Si bien es cierto que, en el caso de la de pólvora, debido a la sensibilidad del material que custodian y trabajan el acceso es complejo, motivo por el cual sería preciso abordar otra medida para mostrar la trayectoria de esta actividad.

Todo ello se podría emprender por separado pero sería viable abarcar las propuestas aquí enmarcadas a través de rutas e itinerarios, no solo de ámbito regional, sino implicando a varias comunidades tanto nacionales, como de países euromediterráneos y del norte 
africano con las que se comparte identidad industrial sumando pasado y actualidad, patrimonio e industria, para crear proyectos de esta envergadura que focalizarán la atención en estratos como el agroalimentario, minero, textil o cerámico, con el fin de conectar propuestas similares en una serie de ejes con denominadores comunes que permitirían potenciar, diversificar y dar visibilidad a unas propuestas que pasarían de la fragmentación local a una visión de conjunto. De este modo sería a la vez posible incidir en la historia industrial de estos territorios, a menudo denostados y alejados de este proceso al no entender que la industrialización es un proceso permeable y adaptable a la realidad de sus promotores, que aquí siguió unas disposiciones diferentes a las zonas consideradas tradicionalmente más industrializadas que no minimizan su importancia.

\subsection{Red de museos industriales y técnico-científicos}

La tan ansiada demanda del "Colegio Oficial y Asociación Ingenieros Industriales Región de Murcia”, quienes custodian la maquinaria de la fábrica de chocolate Tárraga de San Pedro del Pinatar, de crear un museo de la industria regional no se ha convertido en una realidad todavía. Ello deriva en que no se disponga de un centro de referencia, sino que se actúe de manera particular mediante disposiciones municipales y autonómicas que han generado centros propios, distribuidos por el territorio regional y donde las colecciones suelen fusionar referentes de diverso ámbito con los industriales. La creación de un centro específico permitiría gestionar y actuar sobre el patrimonio mueble industrial de una manera eficiente, ya que el no disponer de un organismo de estas características deriva en que se esté perdiendo parte del mismo, el cual en algunos casos es custodiado en centros que no tienen nada que ver con el hilo argumental industrial, en otros se traslada a espacios públicos, decorando rotondas y jardines, o queda en un impasse que afecta a su conservación y mantenimiento, sin olvidar que por su propia disposición es un referente más apto para ser vendido; tanto para seguir con su uso original, como por verse solo aprecio en su peso a la hora de ser convertido en mera chatarra. Por eso, para reforzar esta cuestión, sería también considerable crear una red de museos que los unifiquen y registren de una manera concisa sin temor a equívocos por el enunciado de la institución, del tal modo que se cree una marca para los museos industriales, técnicos o científicos de la región que facilite su difusión y reconocimiento externo.

\subsection{Los otros referentes industriales}

Lo industrial no es solo la fábrica, dentro de su ámbito de acción están otros espacios: los destinados al ocio y las residencias de obreros y empresarios forman igualmente parte de este sustrato y deberían ser tenidos en cuenta a la hora de potenciarlo. Hasta el momento no se ha abogado por impulsarlo al margen de la vertiente arquitectónica modernista del área Cartagena-La Unión que solo ha permitido remarcar una parte de estos elementos; el vinculado a sus promotores. Por el contrario la vivienda obrera ha quedado al margen al minimizar su importancia sin entender que es un testimonio del modelo industrial y social impulsado, lo que deriva en que esté sucumbiendo con la progresión de los tiempos, como ha testimoniado el poblado obrero del Valle de Escombreras (Cartagena) gestado por las 
empresas energéticas ubicadas en él que tras entrar en desuso ha servido para transformarse en suelo industrial. Deberían ser factores a tener en cuenta para regenerarse como nuevos espacios habitacionales y ser capaces, a su vez, de verse como nuevos recursos con mayores implicaciones donde lo cultural y turístico fuera destacado.

Del mismo modo abordar la recuperación del legado inmaterial de algunas actividades industriales abandonas o en riesgo de desaparición permitiría obtener una recopilación de testimonios audiovisuales laborales en primer persona que dejarían constancia de los mismos. Es más, en este caso conviene indicar que la Región de Murcia ha sido un activo dentro del proyecto "MEDINS. Identity is future. The Mediterranean Intangible Space", impulsado por el programa europeo Interreg IIIB MEDOCC, donde una de sus vías de acción era recuperar el mundo laboral, tarea que impulsaría opciones bajo este sustento y que haría factible completar las acciones ya en marcha.

\subsection{Plataforma en defensa del legado industrial regional}

Al margen de todas estas actuaciones, de las que están en curso o podrían realizarse, sería recomendable crear una plataforma propia que unificará y articulará las medidas para proceder a defender los vestigios, materiales e inmateriales, muebles o inmuebles, del sustrato industrial regional. Hasta ahora lo que hay son asociaciones de corte local o sectorial, tal y como testimonian la "Fundación Sierra Minera", la "Asociación de Ingenieros Industriales de la Región de Murcia" o las asociaciones ferroviarias de Murcia y Águilas, que trabajan de manera independiente en defensa de unos intereses que deberían ser comunes. Mientras que por parte de las administraciones regionales y locales hay un interés cada vez más acuciante por implementar medidas sobre el mismo, pero ello a veces se da con la realidad de la falta de recursos económicos y humanos. La creación de una entidad regional específica sobre este campo permitiría dar una visibilidad plena a todo el patrimonio industrial regional, unificar acciones y convertirse en un referente con peso e identidad tanto en el ámbito regional, como a nivel nacional e internacional. Ello ayudaría a legitimar el uso turístico de los referentes industriales, a la vez que se debería abogar por incluir a las empresas en activo en esta fórmula.

\section{CONCLUSIONES}

El turismo industrial es una oportunidad para los bienes industriales. Proyectar acciones turísticas sobre el patrimonio industrial es un modelo que surgió desde los inicios de su reconocimiento y que toma como referente lo realizado sobre el patrimonio cultural. Ello puede suponer una nueva vía para la conservación de los mismos. Y ver bajo su mismo prisma a la industria en activo permite tanto difundirla, como generar una nueva opción al permitir transmitir en primera persona las experiencias y procesos que van desde la fase de producción al consumo del producto.

En la Región de Murcia este modelo se ha impulsado con desigual consideración, pues mientras el patrimonio industrial ha sido considerado un aliado para diversificar la oferta turística regional, la industria viva ha precisado de más tiempo para ser reconocida como una opción posible. De esta manera podemos indicar que la realidad de la oferta de 
propuestas turísticas sobre el sustrato industrial en la Región de Murcia sigue las pautas tradicionales: la mera reunión y exposición de elementos, la creación de productos turísticos consolidados o generar rutas. En paralelo que se han promovido medidas para activar su consideración en la industria en funcionamiento. Pero todavía se podía ir más allá y seguir avanzando en su consolidación con la activación de nuevas iniciativas que reactiven lo realizado y apuesten por nuevas fórmulas. Para ello es preciso reformular lo realizado.

Actualmente el interés por incentivarlo es insuficiente si se compara con el resto de propuestas turísticas y culturales. Falta cualificación y formación para abordarlo. Además, no se cuenta con el apoyo de los sectores industriales que pueden sustentarlo, ni con el compromiso pleno de las administraciones que deberían velar por él. En este punto conviene destacar que ni la declaración de parte de sus referentes industriales como BIC, ni la inclusión de los más significativos en el Plan Nacional de Patrimonio Industrial, han llevado aparejada una mayor consideración de los mismos.

Las actuaciones emprendidas a menudo no acaban configurando un producto turístico, sino que sirven para resaltar un recurso que no cumple con las expectativas de visitas y beneficios económicos proyectados. Además, como se ha podido comprobar, se repiten modelos similares, con pocas variaciones, que acaban por no provocar en el visitante la sensación de novedad. Por otro lado no se es consciente de los daños que la vertiente turística puede incitar tanto en el patrimonio, al no interpretarlo correctamente o al emplearlo sin haber una actuación de consolidación y mantenimiento, como en la industrial al no tomar las medidas correctoras adecuadas, lo que puede perjudicar tanto al trabajador como al visitante. Por último, conviene destacar que no dispone de canales de difusión suficientes. Cuestión que deriva en que pese a lo que hay hecho y se está haciendo, se tenga la sensación de que es algo residual.

Es por ello que para poder paliar estas cuestiones e impulsarlo de manera adecuada, sería preciso abordar nuevas medidas para reforzarlo. Entre ellas destacamos la necesidad de actuar en referentes importantes y significativos. A ello ayudaría la realización de inventarios y estudios previos que permitirían fijar los más atractivos y conocer las implicaciones de los mismos de manera completa y no superficial. De este modo también se evitaría actuar sobre referentes similares y diversificar los sectores industriales vistos bajo sus parámetros.

Tratar de agrupar las acciones turísticas por zonas o áreas, y no por tipos de turismo (termal, natural, rural, deportivo, etc.) permitiría unificar a partir de su diversificación y generar nuevas propuestas a tener en cuenta, las cuales no solo permitirían conocerlas sino promover la difusión de este tipo de turismo provocando un efecto llamada en los visitantes sobre posteriores intervenciones. Un aspecto que se vería reforzado con la creación de una marca distintiva propia que lo conectará con las redes nacionales e internacionales que ya están en activo o que se vayan a impulsar.

Si además se realizará un plan estratégico que permitiera desglosar esta acción de forma coordinada y completa, sería factible enmarcar las posibilidades y dificultades de las propuestas a realizar, conjugar el patrimonio con la industria en activo, así como reforzar la información, generar una correcta señalización que facilite su localización, cuidar los accesos a los mismos y trabajar en propuestas no estacionales que permitan atraer perfiles de visitantes diferentes. 
Ello sumado a la necesidad de contar con la población local y los entes sociales servirían para mostrar el valor que pueden adquirir los referentes industriales, ya que pueden ser partícipes de estas cuestiones mediante su colaboración y servir de base para la creación de nuevos puestos de trabajo.

La difusión hemos comprobado que debe ser reforzada. Para ello hay que trabajar en varias vías: lograr que la visita sea entendible, trabajando tanto la labor de los guías, como de los trabajadores que asumen esta tarea; elaborar guías y sumar la vertiente turística industrial a las aplicaciones móviles que están en activo. Así como mostrar lo realizado en esta vertiente en ferias y lograr incluirlo entre las ofertas de los touroperadores.

En el caso de la empresa en activo, junto con estos puntos, sería asumible la creación de un programa de incentivos fiscales a quienes se sumen a esta iniciativa. Así como reforzar e implementar la difusión de este turismo, especialmente entre las PYMES y las empresas familiares, quienes a menudo quedan alejadas de este proceso.

Todo ello sería más fácil de canalizar a través de la creación de un centro o entidad especifica que coordine las actuaciones en esta materia, así como con un programa de rescate de elementos industriales en peligro.

De este modo el turismo industrial podría convertirse en una acción sostenible que permita tanto el mantenimiento del patrimonio industrial, como de la actividad industrial actual, si va en contra de ellos no tiene sentido. Ya que su mantenimiento y conocimiento es lo que realmente nos permite poder apreciar no solo el desarrollo y la evolución industrial de la sociedad murciana, sino también el sustrato cultural entorno a la misma.

\section{BIBLIOGRAFÍA}

AGUILAR CIVERA, I. (1998): Arquitectura industrial: Concepto, método y fuentes. Valencia, Museu d'Etnologia de la Diputació de València.

BIEL IBÁÑEZ, P. y CUETO ALONSO, G. (2011): 100 Elementos del patrimonio industrial en España. Gijón, TICCIH-España, CICEES.

CAAMAÑO FRANCO, I. (2011): «La comercialización del turismo industrial», ROTUR/ Revista de Ocio y Turismo, $\mathrm{n}^{\circ}$ 4, pp. 161-180.

CAÑIZARES RUIZ, M.C. (2011): «Patrimonio, parques mineros y turismo en España», Cuadernos de Turismo, $\mathrm{n}^{\circ} 27$, pp. 133-153.

CONESA LÓPEZ, F. (2000): Guía de la vía verde del Noroeste y Camino de la Vera Cruz. Murcia, Asociación Amigos del Camino de la Vera Cruz.

ELÍAS PASTOR, L. V. (2006): El turismo del vino. Otra experiencia de ocio. Bilbao, Universidad de Deusto.

GALLEGO VALIÑA, M.Á. (2011): «Turismo industrial: El caso alemán», ROTUR/ Revista de Ocio y Turismo, $\mathrm{n}^{\circ} 4$, pp. 117-138

GRIÑÁN MONTEALEGRE, M., LÓPEZ SÁNCHEZ, M. y PALAZÓN BOTELLA, M.D. (2008): «Propuesta de una ruta de la industria conservera en la Región de Murcia», Imafronte, $\mathrm{n}^{\circ} 19-20$, pp. 105-118.

GRIÑÁN MONTEALEGRE, M. y PALAZÓN BOTELLA, M.D. (2013): «Las fábricas de luz como modelos arquitectónicos y urbanos en peligro en la Región de Murcia (España)», Apuntes. Revista de estudios sobre patrimonio cultural, nº 26 (2), pp. 90-101. 
HIDALGO GIRALT, C. (2010): El patrimonio minero-industrial y ferroviario: Nuevos usos para nuevos turismos. Tesis Doctoral. Universidad Autónoma de Madrid.

HUDSON, K. (1966): Industrial Archaeology: An Introduction. London, John Baker.

HUDSON, K. (1979): World Industrial Archaeology. Cambridge, University Press.

MANTECA MARTÍNEZ, J.I. y GARCÍA GARCÍA, C. (2005): «Valorización del patrimonio geológico y minero de La Unión-Murcia: Propuesta preliminar de adaptación de la antigua mina "Agrupa Vicenta" para uso turístico», en XIV Jornadas Patrimonio Histórico. Intervenciones en el patrimonio arquitectónico, arqueológico y etnográfico de la Región de Murcia. Murcia, Servicio de Patrimonio Histórico, D.L., pp. 200-206. MANTECA MARTÍNEZ, J.I. y GARCÍA GARCÍA, C., RÓDENAS ROZAS, F. J. (1999): «Ruta Minera “Carretera del 33”. La Unión (Murcia)» en Simposio sobre el patrimonio geológico y minero. IV Sesión científica de la Sociedad Española para la Defensa del Patrimonio Geológico y Minero. Córdoba, S. D., pp. 176-191.

MANTECA MARTÍNEZ, J.I., GARCÍA-GARCÍA, C., BERROCAL CAPARRÓS, Ma . C., JIMÉNEZ MEDINA, P., GARCÍA FERNÁNDEZ, G., COLLADO ESPEJO, P. E. y RECIO SEVILLA, A. (2005): «Puesta en valor del patrimonio cultural de la Cuesta de las Lajas y Carretera del 33. Aspectos geológico-mineros y medioambientales» en XIX Jornadas de Patrimonio Cultural de la Región de Murcia: Cartagena, Alhama de Murcia, La Unión y Murcia. Murcia, Ligia, pp. 671-682.

MARKUA, A. (2011): «Revisión del proceso de valorización de los recursos base del turismo industrial», ROTUR/Revista de Ocio y Turismo, $\mathrm{n}^{\circ}$ 4, pp. 57-88.

MARTÍNEZ CARRIÓN, J.M. (2002): Historia económica de la región de Murcia: siglos XIX y XX. Murcia, Editora Regional de Murcia.

NADAL, J. y CATALÁN, J. (1994): La cara oculta de la industrialización. La modernización de los sectores no líderes (siglos XIX y XX). Madrid, Alianza Editorial.

PALAZÓN BOTELLA, M.D. (2011): De la arquitectura al patrimonio industrial en la Región de Murcia. Tesis doctoral. Universidad de Murcia.

PARDO ABAD, C. (2002): «Rutas y lugares de patrimonio industrial en Europa: Consideraciones sobre su aprovechamiento turístico», Espacio, Tiempo y Forma, no 15 , pp. 69-94.

PARDO ABAD, C. (2004): «La reutilización del patrimonio industrial como recurso turístico. Aproximación geográfica al turismo industrial», Treballs de la Societat Catalana de Geografía, $\mathrm{n}^{\circ}$ 57, pp. 7-32.

PARDO ABAD, C. (2008): Turismo y patrimonio industrial. Un análisis desde la perspectiva territorial. Madrid, Ed. Síntesis.

PARDO ABAD, C. (2010): «El patrimonio industrial en España: Análisis turístico y significado territorial de algunos proyectos de recuperación», Boletín de la Asociación de Geógrafos Españoles, n ${ }^{\circ}$ 53, pp. 239-264.

PEÑALVER TORRES, M.T. (2002): «La arquitectura industrial: Patrimonio histórico y utilización como recurso turístico», Cuadernos de Turismo, no 10, pp. 155-166.

PORTELA MAQUIEIRA, S., MARTÍNEZ CARBALLO, M. y GUILLÉN SOLÓRZANO, E. (2015): «Beneficios de la implantación de la Marca Q de turismo industrial», Pasos, $\mathrm{n}^{o} 13(4)$, pp. 757-769. 
VALENZUElA RUBiO, M., PALACIOS GARCÍA, A. J., HIDALGO GIRALT, C. (2008): «La valoración turística del patrimonio minero en entornos rurales desfavorecidos. Actores y experiencias», Cuadernos de Turismo, n 22 , pp. 231-260.

VV.AA. (2008): El patrimonio cultural inmaterial. Definición y sistemas de catalogación. Murcia, Comunidad Autónoma de la Región de Murcia. Consejería de Cultura, Juventud y Deportes. Dirección General de Bellas Artes y Bienes Culturales. Servicio de Patrimonio Histórico.

\section{WEBGRAFÍA}

Boletín Oficial de la Región de Murcia. Disponible en http://www.borm.es/borm/vista/ principal/inicio.jsf

Diario La Opinión. Disponible en http://www.laopiniondemurcia.es/

Diario La Verdad. Disponible en http://www.laverdad.es/

European Route of Industrial Heritage. Disponible en http://www.erih.net/

Instituto del Patrimonio Cultural de España. Disponible en http://ipce.mcu.es/

Instituto para la Calidad Turística Española. Disponible en http://www.icte.es/ESP/m/1/ Inicio/Inicio

Itinéraires culturels du Conseil de l'Europe. Disponible en http://www.coe.int/t/dg4/cultureheritage/culture/routes/default_FR.asp

Murcia Turística. Disponible en http://www.murciaturistica.es/

Red Española de Turismo Industrial. Disponible en http://www.turismoindustrial.es/

Región de Murcia Digital. Disponible en http://www.regmurcia.com/

Rutas del Vino de España. Disponible en http://www.wineroutesofspain.com/

Sistema Regional de Museos. Disponible en http://www.museosdemurcia.com/museos. sistema_regional_museos

TICCIH-ESPAÑA. Disponible en http://ticcih.es/

Turinde. Disponible en http://www.turinde.com

Xarxa de Turisme Industrial de Catalunya. Disponible en http://www.xatic.cat/ 